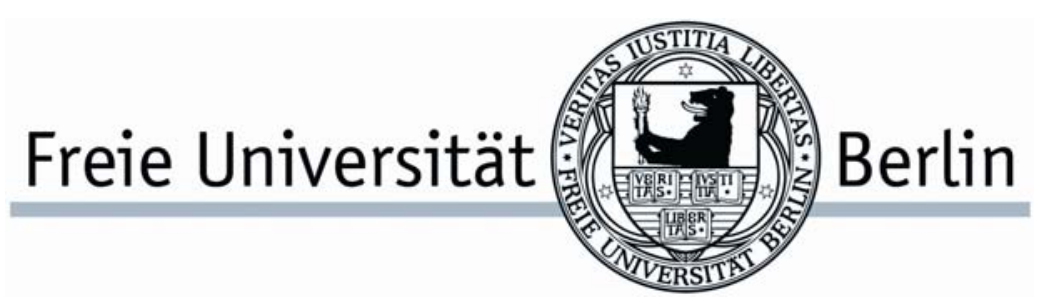

Diskussionsbeiträge des Fachbereichs Wirtschaftswissenschaft der Freien Universität Berlin

Volkswirtschaftliche Reihe

2007/8

\title{
What's the Monetary Value of Distributive Justice
}

Giacomo Corneo and Christina M. Fong 


\title{
What's the Monetary Value of Distributive Justice?
}

\author{
Giacomo Corneo And Christina M. Fong
}

May 17, 2007

\begin{abstract}
This paper proposes a model that can be implemented to estimate the willingness to pay for distributive justice, defined as distribution according to desert. We derive a formula that allows one to recover the willingness to pay for distributive justice from fiscal data and the estimated coefficients of a probit regression. Using this formula and data from a 1998 Gallup Social Audit, we find that on average the monetary value of justice for US households amounts to about one fifth of their disposable income. Moreover, we find evidence of markedly heterogeneous preferences for justice along the lines of race and education.
\end{abstract}

Keywords: Distributive Justice, Governmental Redistribution, Fairness

JEL codes: D63, H24

We thank Horst Zimmermann for encouragement and two referees, the editor Thomas Piketty, Michele Bernasconi, Sam Bowles, Andrew Clark, Claudio Lucifora, John Roemer, Carsten Schröder, Joel Slemrod and Christian Toft for helpful comments. Of course, the usual caveat applies. Affiliations. Corneo: Free University of Berlin, CEPR, CESifo, IZA. Fong: Carnegie Mellon University. Address: Giacomo Corneo, Dept. of Economics, Free University of Berlin, Boltzmannstr. 20, 14195 Berlin, Germany (email: gcorneo@wiwiss.fu-berlin.de). 


\section{INTRODUCTION}

As proposed long ago by Thurow (1971), a just income distribution may be seen as a pure public good. This paper develops a method of estimating the monetary value of that public good and identifying how this value differs across subgroups of the population.

Estimating the monetary value of distributive justice is important for assessing the efficiency implications of governmental action. In many countries, a large share of the government's budget is devoted to redistributing income, supposedly for equity reasons. Since governmental redistribution is costly for society, some knowledge of society's willingness to pay for distributive justice is required in order to evaluate whether that public good is efficiently provided.

Moreover, assessing how equity concerns vary in the population can deliver novel insights into the political economy of income redistribution. As is well known, there is a wide spectrum of attitudes toward redistribution, even within groups of individuals with similar market incomes. Different preferences for distributive justice constitute a potential key factor driving different demands for redistribution and leading to different political outcomes.

There are various principles of distributive justice; chief among them are equity, equality and need. In this paper, we assume that people have a preference for equity, i.e., for living in a society where "one gets what one deserves, and deserves what 
one gets". That is, we posit that the public good desired by people is distribution according to desert. We propose a method for estimating the monetary value of distributive justice thus defined that is grounded on an explicit microeconometric model. The proposed method employs survey data, but without running into the usual difficulties encountered by survey methods for measuring the willingness to pay for public goods.

Our theoretical framework is a stylized model of demand for governmental redistribution of income in which demand is driven by both selfish pecuniary motives and a concern for justice. Crucially, the way in which that concern affects demand for redistribution depends on individuals' beliefs regarding the fairness of market incomes. Individuals who believe market outcomes to be determined mainly by family background and luck - i.e. factors beyond one's control - require governmental reduction of inequality to feel that society is just. Individuals who view market incomes as resulting from effort and hard work instead perceive laissez-faire as equitable.

For an individual who believes that the pre-fiscal distribution of income is unfair, her willingness to pay for justice is defined as the maximal amount of money that she would be ready to sacrifice in order to prevent the actual income distribution from switching to the distribution that would arise under laissez-faire. For somebody who believes that the pre-fiscal distribution is fair, her willingness to pay for justice is defined as the maximal amount of money that she would be ready to sacrifice in 
order to switch to laissez-faire.

Our basic model posits individuals with different beliefs but common preferences. The extended model allows for heterogenous preferences; the willingness to pay for justice can then be decomposed into a part which is common to everybody and typespecific parts.

We embed the model of demand for governmental redistribution into a random utility model. Estimating the latter requires only measures of support for or opposition to redistribution, beliefs about the fairness of market outcomes, and pre-fiscal incomes. We derive a simple formula that allows one to recover the willingness to pay for distributive justice from the estimated coefficients of a probit regression and fiscal data. Estimating type-specific willingnesses to pay simply requires appropriate interaction terms in the probit regression.

As a first application of the proposed estimation method, this paper estimates the value of distributive justice, i.e. distribution according to desert, in the United States. Using a large representative sample drawn in 1998, we find that Americans' willingness to pay for distributive justice is substantial: on average, it amounts to about 20 percent of their disposable income. Moreover, we find that preferences for justice differ according to race and education.

The numerical results obtained from our empirical exercise must be qualified: the theoretical framework that we employ entails strong simplifications and the empirical 
proxies for our theoretical variables are far from ideal. Hence, much caution is required when interpreting the estimated willingnesses to pay. More interesting than the particular numbers obtained, in our view, is the robust finding that in the US concerns for distributive justice do matter in monetary terms.

The other major insight from our empirical exercise is that the willingness to pay for justice, as a fraction of an individual's income, depends on her race and education. For any given income and beliefs about the fairness of market outcomes, white individuals with at least some higher education display a remarkably higher willingness to pay for justice than the rest of the population. Thus, distributing income according to desert is of special concern for the educated white. Possibly, noneducated members of racial minorities endorse another view of distributive justice, one that puts less emphasis on desert and more on needs or on equality tout court.

Despite this heterogeneity in the value of distributing income according to desert, differences in demand for governmental redistribution turn out to be mostly driven by differences in the beliefs about the fairness of the market system. We find that differences in those beliefs are not only more powerful than differences in preferences, they are also a stronger determinant of political attitudes than the pre-fiscal income of individuals.

The current paper relates primarily to three recent strands in the literature on redistributive politics. The first consists of theoretical papers that incorporate a 
concern for fairness into models of political redistribution of income. A recent example is Alesina and Angeletos (2005), who aim at explaining the coexistence of large welfare states and laissez-faire societies, each associated with different perceptions about the sources of economic disparities. In their model, fairness enters the voters' utility function and voters may face a tradeoff between their own consumption and justice. Piketty (1995) chooses a more extreme modeling option, according to which voters only care about fairness, i.e. they vote so as to maximize a social welfare function. Even if they share the same welfare function, individuals vote differently because they have different beliefs about the market return to effort.

The second strand of literature consists of econometric investigations of survey data on attitudes toward governmental redistribution of income. It includes papers by Fong (2001), Corneo and Grüner (2002) and Alesina and La Ferrara (2005). Those studies show that individuals' beliefs about how fair market outcomes are contribute significantly to explaining their demands for governmental redistribution. As argued by Corneo (2001), concerns with desert may be affected by cultural factors and their intensity varies across countries. The probit regressions presented in this paper belong to the same family as those in that literature.

Finally, our paper is related to empirical investigations on how people think about distributive justice and earnings inequality. As documented by Schokkaert (1998), a large body of empirical research on opinions of distributive justice, mainly coming 
from sociology and psychology, delivers little support to a welfarist notion of justice. Rather, in judgements about macro-justice, the desert criterion is found to play a crucial role. Osberg and Smeeding (2006) compare attitudes in various countries toward what individuals in specific occupations "do earn" and what they "should earn". They stress that even within nations people do not all agree about what constitutes a fair distribution of income. The findings in the current paper support the idea that judgements about distributive justice are based on heterogeneous criteria. Interestingly, Osberg and Smeeding find more polarization in attitudes toward inequality among Americans than in other countries.

The rest of the paper is organized as follows. In Sect. 2 we describe our econometric model. Sect. 3 discusses our data and measures and Sect. 4 presents our estimation results. In Sect. 5 we show how the model can be generalized to heterogeneous preferences and estimate the generalized model. Sect. 6 concludes.

\section{ThEORETICAL FRAMEWORK AND EMPIRICAL STRATEGY}

Individuals derive utility from the consumption of a numeraire good, $C$, and from the perception of a just distribution of income, $J$. All other determinants of utility being held constant, we assume that perceiving the income distribution as unjust rather than just decreases an individual's utility. Let us assume that utility is cardinally measurable and unit comparable and takes the form 


$$
U=\alpha \log C+\beta J
$$

where $\alpha$ and $\beta$ are nonnegative scalars. The variable $J \in\{-1,1\}$ takes the value 1 if the individual thinks that the allocation of resources in society is just and -1 otherwise. Thus, $2 \beta$ represents the utility gain for the individual if she feels that justice is realized. Let $W$ denote the willingness to pay for justice, i.e. the maximal amount an individual is willing to sacrifice in order to establish a just society. It is implicitly defined by

$$
\alpha \log (C-W)+\beta=\alpha \log C-\beta
$$

Solving this equation yields

$$
W=\left[1-\exp \left(\frac{-2 \beta}{\alpha}\right)\right] C
$$

Hence, individuals are willing to sacrifice a maximal fraction $1-\exp \left(\frac{-2 \beta}{\alpha}\right)$ of their disposable income to obtain justice. ${ }^{1}$

\footnotetext{
${ }^{1}$ The willingness to accept injustice, i.e. the minimal amount an individual requires in order to give up justice, is given by $\left[\exp \left(\frac{2 \beta}{\alpha}\right)-1\right] C$.

In the first version of this paper (Corneo and Fong, 2005), we assumed that utility linearly increases with disposable income. In that framework, the willingness to pay for justice does not depend on income and equals the willingness to accept injustice. While that assumption is not palatable, the resulting model imposes less requirements on the fiscal data needed for gauging the value of justice.
} 
The existence or lack of distributive justice is related to two factors: the fairness of market outcomes, $f$, and the governmental redistribution of incomes, $R$. Let $f$ be 1 if market incomes are perceived to be fair and 0 otherwise. Similarly, let $R$ be 1 if the government redistributes income and 0 otherwise. Justice is assumed to be done if either market outcomes are fair and government does not redistribute or market outcomes are unfair and governmental redistribution occurs:

$$
\begin{gathered}
J=1 \Leftrightarrow\{f \neq R\} \\
J=-1 \Leftrightarrow\{f=R\} .
\end{gathered}
$$

Using these relationships, we can express utility as a function of $f$ and $R$. Namely, an agent's utility may be written as

$$
U_{R}=\alpha \log C_{R}+\beta(1-2 f)
$$

under $R=1$ and as

$$
U_{N}=\alpha \log C_{N}+\beta(2 f-1)
$$

under $R=0$. In this formulation, $C_{R}$ and $C_{N}$ respectively denote consumption with

The aggregate value of justice estimated according to that model is somewhat larger than the one estimated in the model of the current paper. 
and without redistribution. Equivalence with (1) can easily be checked using the above definition of justice. By way of an example, suppose that market outcomes are unfair: $f=0$. If there is no governmental redistribution of income, $R=0$; then, $J=-1$. Since $U=U_{N}$ if $R=0$, we obtain $\beta J=-\beta$. The three remaining cases can be checked in a similar fashion. Notice that $W$ measures the willingness to pay for distributional justice, not for governmental redistribution. The two notions only coincide if one thinks that market outcomes are unfair. The theoretical model is closed by the assumption that individuals support governmental redistribution of income if and only if they achieve higher utility under redistribution.

In order to bring the theoretical framework to the data, we express it in terms of a random utility model. Let utility in the case of redistribution be given by

$$
U_{R}=\alpha \log C_{R}+\beta(1-2 f)+x^{\prime} \gamma_{R}+\varepsilon_{R}
$$

and utility in the case of absence of any redistribution be given by

$$
U_{N}=\alpha \log C_{N}+\beta(2 f-1)+x^{\prime} \gamma_{N}+\varepsilon_{N}
$$

In the above equations, $x$ is a vector of observable individual characteristics, the first element of which is normalized to $1 . \varepsilon_{R}$ and $\varepsilon_{N}$ represent the error terms. 
Preferences affect attitudes according to

$$
\operatorname{Pr}\left[d=1 \mid C_{N}, C_{R}, f, x\right]=\operatorname{Pr}\left[U_{R}>U_{N}\right]
$$

where $d$ is a dummy variable which equals 1 if the individual supports governmental redistribution of income and 0 otherwise.

Let $y$ denote the individual's market income. In the absence of redistribution, market income and consumption coincide, i.e. $C_{N}=y$. In the presence of redistribution, consumption depends on the functional form of the redistributive scheme. We consider two models of governmental redistribution: a linear scheme and one with constant progressivity.

2.1. Linear redistribution. Assume that $C_{R}=y(1-t)+z$, where $t$ and $z$ are the parameters of an affine redistributive system. According to some empirical studies, e.g. Roemer et al. (2003), actual systems of redistribution are described rather well by affineness.

Inserting the above definitions of $C_{N}$ and $C_{R}$ in (3) and (4), and substituting the resulting equations into (5), one obtains

$$
\operatorname{Pr}[d=1 \mid y, f, x]=\operatorname{Pr}\left[\alpha \log (1-t+z / y)+\beta(2-4 f)+x^{\prime} \gamma+\varepsilon>0 \mid y, f, x\right]
$$


where $\varepsilon=\varepsilon_{R}-\varepsilon_{N}$ and $\gamma=\gamma_{R}-\gamma_{N} \cdot{ }^{2}$

The relationship (6) can be estimated as a binary probit model. Let $\widehat{b}_{f}=\sigma b_{f}$ and $\widehat{a}_{y}=\sigma a_{y}$ be the estimates of the coefficients on $f$ and on the income-dependent variable $\log (1-t+z / y)$, respectively, where $b_{f}$ and $a_{y}$ are probit estimates and $\sigma$ is the (unknown) variance of the error term of the probit equation. ${ }^{3}$

Note that

$$
\alpha=\sigma a_{y}
$$

and

$$
-4 \beta=\sigma b_{f}
$$

Therefore,

$$
\frac{2 \beta}{\alpha}=\frac{-b_{f}}{2 a_{y}}
$$

Inserting this term into (2) yields

$$
j \equiv \frac{W}{C}=1-\exp \left(\frac{b_{f}}{2 a_{y}}\right)
$$

which is the formula for quantifying the value of distributive justice under an affine

\footnotetext{
${ }^{2}$ If one assumes that $\gamma_{R}=\gamma_{N}$, then $x^{\prime} \gamma$ drops out of the empirical model and attitudes towards redistribution are completely determined by pecuniary incentives and a desire for distributive justice.

${ }^{3}$ To obtain the probit model, one assumes that the distribution of the error is a standard normal and thus $\sigma=1$. Since in general the variance of the error term cannot be identified, only the ratio of the coefficient to $\sigma$ is identified.
} 
redistributive scheme.

2.2. Constant progressivity. The second redistributive scheme that we consider has

$$
C_{R}=s C_{N}^{r}
$$

and $C_{N}=y$, as before. The parameter $r>0$ is the coefficient of residual progression:

$$
r=\frac{d \log C_{R}}{d \log C_{N}}
$$

The smaller $r$, the more progressive is governmental redistribution of income.

Inserting the above definitions of $C_{N}$ and $C_{R}$ in (3) and (4), and substituting the resulting equations into (5), one obtains

$$
\operatorname{Pr}[d=1 \mid y, f, x]=\operatorname{Pr}\left[\alpha \log (s)+(r-1) \alpha \log (y)+\beta(2-4 f)+x^{\prime} \gamma+\varepsilon>0 \mid y, f, x\right] .
$$

Again, this relationship can be estimated as a binary probit model. Let $\widehat{B}_{f}=\sigma B_{f}$ and $\widehat{A}_{y}=\sigma A_{y}$ be the estimates of the coefficients on $f$ and $\log (y)$, respectively, where $B_{f}$ and $A_{y}$ are probit estimates and $\sigma$ is the variance of the error term of the probit equation. 
Note that

$$
\alpha(r-1)=\sigma A_{y}
$$

and

$$
-4 \beta=\sigma B_{f}
$$

Therefore,

$$
\frac{2 \beta}{\alpha}=\frac{(1-r) B_{f}}{2 A_{y}}
$$

Inserting this expression into (2) yields

$$
j \equiv \frac{W}{C}=1-\exp \left[\frac{(r-1) B_{f}}{2 A_{y}}\right]
$$

which is the formula for quantifying the value of distributive justice under a redistributive scheme with constant progressivity.

\section{DATA AND MEASURES}

The assumptions of the model impose certain requirements on the data. First, the model calls for a measure of pre-tax and pre-transfer income. Second, it calls for a measure of absolute support for and opposition to redistribution rather than support for more or less redistribution relative to the status quo. Third, it calls for a measure that asks about a general redistributive policy that can achieve justice for society as a whole. Widely available questions that ask about attitudes to "welfare" or "helping 
the poor" may be inappropriate because they might be interpreted as asking about small means-tested programs such as TANF or the former AFDC in the United States. These programs may help the poor without having much financial impact on those who never expect to qualify for benefits, because the relatively small costs of the program are shared by many taxpayers.

An additional concern is to avoid using "target-specific" beliefs about the fairness of market incomes. When a redistributive policy targets a specific group of people, beliefs about the causes of income for that specific group - referred to as target-specific beliefs - have much larger effects on support for that policy than beliefs about the causes of income for people who are not in the target-group (Fong, 2005).

Finally, the publicly available social surveys tend to contain many "double-barreled" questions - namely, questions that ask about more than one concept at a time. While it is difficult to avoid double-barreled questions altogether, it is important to avoid those that would introduce serious confounds into the analysis. ${ }^{4}$

3.1. Data. With these considerations in mind, the best data set for our purposes turns out to be the Gallup Organization 1998 Social Audit titled "Haves and HaveNots" (Gallup Organization, 1998). It is a national sample of the United States containing 5001 respondents of the ages 18 years and older. The data set over-

\footnotetext{
${ }^{4}$ For example, there was a question that simultaneously asked about whether or not the distribution of income is fair and whether or not it should be more equal, thus relating to both our dependent and independent measures. This question is clearly inappropriate.
} 
samples the poor, so we use sample weights to make it nationally representative. However, the sample weights have little effect on our estimates.

3.2. Measures. Tables A1 and A2 in the Appendix present summary statistics and the exact wording of the attitudinal measures used in our analysis. Our dependent measure of demand for governmental redistribution is a binary variable that asks whether or not "our government should redistribute wealth by heavy taxes on the rich". There are two responses to this question - "should" and "should not" - plus "don't know". Out of the whole nationally representative sample, 44.69 percent said the government should redistribute, 51.52 percent said "should not", and 3.79 percent said "don't know" or did not respond. ${ }^{5}$ We code the responses so that support for redistribution is one and opposition to redistribution is zero. ${ }^{6}$

While none of the potential dependent measures in the data sets we searched were perfect, this question is one of the best because it asks about support for general redistribution of wealth - suggesting a large program that is likely to have a substantial financial impact on much of the population, rather than a small program that concentrates its financial impact on the poor. However, the question also describes a program that targets the rich more than the poor, so we are careful to avoid regressing our dependent measure on target-specific beliefs about the causes of

\footnotetext{
${ }^{5}$ Throughout this section we report nationally representative weighted proportions. The unweighted proportions are virtually the same as the weighted proportions.

${ }^{6}$ We code "don't know" as missing, because our model addresses the population of people who know their preferences.
} 
wealth.

Beliefs about the fairness of market outcomes are recovered from two survey questions about the roles of effort and circumstances beyond individual control in causing, respectively, poverty and wealth. These questions have nearly identical wording and response scales. The one about causes of poverty is: "Just your opinion, which is more often to blame if a person is poor - lack of effort on his or her part, or circumstances beyond his or her control? 1) Lack of effort 2) Luck or circumstances beyond his/her control, 3) Both, 4) Don't know." We refer to this question as WHYPOOR. Out of the whole nationally representative weighted sample, 42.80 percent said lack of effort explained why people are poor, 40.59 percent said "luck or circumstances", 13.95 percent said "both", and 2.66 percent said they "don't know" or did not respond.

The question about causes of wealth is: "Just your opinion, which is more often to blame if a person is rich -strong effort to succeed on his or her part, or luck or circumstances beyond his or her control? 1) Strong effort 2) Luck or circumstances beyond his/her control 3) Both, 4) Don't know." We refer to this question as WHYRICH. Out of the whole nationally representative weighted sample, 53.22 percent said strong effort explained why people are rich, 31.89 percent said "luck or circumstances", 11.34 percent said "both", and 3.56 percent said they "don't know" or did not respond.

Our theoretical model posits people with beliefs that are both "strong" and "gen- 
eral". By strong beliefs, we mean certain beliefs that either effort matters (i.e. that market outcomes are fair) or that luck matters (i.e. that market outcomes are unfair). By general beliefs, we mean beliefs that the causes of income are the same for everyone. Therefore, when estimating the value of justice, we merely use the sub-sample of respondents who had strong and general beliefs - that is, those who either said that lack of effort causes poverty and strong effort causes wealth or that bad luck causes poverty and good luck causes wealth.

While this way of estimating the value of justice closely follows the theoretical model, it leads us to neglect a considerable amount of information, as about half of our sample does not consist of respondents with strong and general beliefs. Hence, we also investigate a second set of regressions using a different measure of beliefs about fairness that is available for over 97 percent of the sample. This measure and the resulting estimates are presented in Appendix A.

As a proxy for market income, we employ annual pre-tax, pre-transfer household income. Income was measured in nine categories. We specify it as a single measure by representing each category with an estimate of the median income of the people in that category. We obtain the category medians for income levels up to $\$ 100,000$ from the concurrent March Supplement to the Current Population Survey. ${ }^{7}$ For

\footnotetext{
${ }^{7}$ For each income category in the Gallup survey, there is a set of smaller income categories in the CPS. For each Gallup income category, we use the CPS income category cutoff point that is closest to the 50th percentile.
} 
income levels greater than $\$ 100,000$, we estimate the category median using data on the distribution of income up to $\$ 250,000$ or more from the 2000 Current Population Survey. ${ }^{8}$

When estimating model (6), we need numerical values for the parameters of the redistributive scheme, $t$ and $z$. Our dependent variable asks whether the government should redistribute, without specifying the extent of redistribution. Since redistribution does occur in the United States, a natural interpretation of the survey question is whether the government should keep redistributing at its actual level. Under this interpretation, the $t$ and $z$ of our theoretical model are the actual ones. Alternatively, the extent of redistribution conjectured by respondents might have been larger than the actual level. However, since we do not know what that conjecture could have possibly been, we stick to the first interpretation and look for parameters that depict the actual system of redistribution as precisely as possible.

To the best of our knowledge, the latest attempt to calibrate the US redistributive scheme as a linear one is Roemer et al. (2003). We adopt the results of that study for our estimation, with some minor adjustments for changes in public expenditures from 1991 to 1998 . Accordingly, we posit $t=0.243$ and $z=5,249 .^{9}$

\footnotetext{
${ }^{8}$ See Table HINC-07 of the Detailed Household Income Tables: 2000, from the 2001 Current Population Survey March Supplement release.

${ }^{9}$ Roemer et al. (2003) find that the lump-sum transfer is 2,036 USD. Their estimation refers to transfer per adult in 1991. Our estimation is obtained by multiplying 2,036 by the average number of adults per household and by the nominal growth factor of public expenditure in the period 1991-1998.
} 
The structural estimation of the theoretical model employs only an income-dependent variable and beliefs about the fairness of market incomes as regressors. In order to check the robustness of our results, we also run regressions with control variables. Including a large number of controls has advantages and disadvantages. The main advantage is that it helps address concerns about potential missing variables biases in the coefficient on beliefs about fairness of market incomes. More specifically, including a large number of proxies for current and expected future financial security helps address concerns that the means and variances of current and expected future income may be correlated with beliefs that market incomes are fair and may bias the coefficient on beliefs upward if they are missing or poorly measured. The main disadvantage of including a large number of proxies for financial security is that it introduces multicollinearity with current income and makes it difficult to estimate the coefficient on income.

To assess this trade-off, we examine the sensitivity of the coefficients on the belief about fairness and on income to specification changes. Along with a structural specification that includes only the beliefs measure and income, we present an intermediate specification that controls for age, age squared, four age-group dummies, a dummy for being white, a dummy for being male, the interaction between the dummies for white and male, five education dummies, a dummy for being married, a dummy for having one or more dependent children under the age of 18 in the household, and 
dummies for living in a suburban area or a rural area (as opposed to an urban area); and a full specification that includes additional objective and subjective indicators of socioeconomic position and financial security. These additional controls are: seventyfive occupation dummies, a dummy for being a union member, dummies for being employed part-time and being unemployed (as opposed to being employed full-time), a dummy for owning a home, the value of the household's non-home assets (ten dummies), subjective worries about paying bills (three dummies), and three dummies for having had too little money in the past year to pay for, respectively, medical bills, food, and clothing. The Gallup data set does not include geographical variables (e.g., state of residence). However, the detailed information about occupation, employment status, population density of residence (i.e., rural, suburban or urban), union membership, and so on, control for many of the economic differences between people living in different states.

\section{Baseline Results}

Tables 1 and 2 present the probit results using the measure of beliefs about market fairness constructed from WHYPOOR and WHYRICH. They are based on the subsample of respondents who had strong and general beliefs about the causes of poverty - namely, those who replied either that effort levels cause both poverty and wealth or that luck or circumstances cause both poverty and wealth. Columns 1, 2 and 3 in each table present, respectively, the structural, intermediate, and full specifications. 
Table 1 reports estimates based on model (6), i.e. a linear redistributive scheme; Table 2 refers to the constant progressivity redistributive scheme posited in model (8). In Appendix A, we report the corresponding findings for probit equations using our alternative measure of beliefs and a much larger sample. As it turns out, the results are not affected very much by the change in the beliefs measure and sample size.

\section{[PLEASE INSERT TABLES 1 AND 2 ABOUT HERE]}

As shown by Table 1, the belief that effort causes wealth and poverty - compared to the omitted category of believing that luck or circumstances cause wealth and poverty - has a negative and highly significant effect on support for redistribution in every specification. The table shows that the coefficient on the belief measure is virtually unaffected by specification changes. When we move from the structural specification to the intermediate specification, the coefficient on the belief about market fairness stays roughly the same, changing from -0.81 to -0.82 . When moving from the intermediate to the full specification the magnitude of the coefficient on beliefs again stays roughly the same, decreasing to -0.80 .

The transformed income variable also has a highly significant effect on support for redistribution in every specification. The transformed variable is inversely related to income, so income itself has a negative effect on support for redistribution, as 
expected. However, the coefficient on transformed income is quite sensitive to specification changes. Moving from the structural to the intermediate specification reduces the magnitude of the coefficient by 33 percent. Moving from the intermediate to the full specification reduces the magnitude of the coefficient by 41 percent. Thus, for the purpose of estimating the coefficient on transformed income, the common practice of including as many control variables as possible is clearly inappropriate.

The results are similar in the case of nonlinear redistribution, as shown by Table 2. The coefficients on the beliefs about market fairness are virtually the same as in Table 1, ranging from -0.80 in columns 1 and 3 to -0.812 in column 2 . The coefficient on the log of income has a highly significant negative effect in columns 1 and 2 , and a marginally significant negative effect in column 3. However, the coefficient on the log of income is very sensitive to the specification. When we move from the structural specification to the intermediate specification, the magnitude of the coefficient falls by 28 percent. When we move from the intermediate to the full specification, the magnitude of the coefficient falls by 41 percent. Given these findings, the full specification is clearly inappropriate. Below, we use the structural specification to calculate our baseline estimates of the value of justice. As we will explain, the structural specification yields the most conservative estimates of the value of justice.

Baseline estimates of the value of justice. The value of distributive justice is given by Equation (2). Accordingly, individuals' valuations of distributive justice 
equal a fraction $j=1-\exp (-2 \beta / \alpha)$ of their disposable income. We now quantify that fraction under the two redistributive schemes posited above.

Linear redistribution. Table 1 gives us estimates of $b_{f}$ and $a_{y}$ for a household with strong general beliefs. Substituting the estimates of $b_{f}, a_{y}$ from column 1 of Table 1 into formula (7), one obtains an estimated value of $j=.270$.

This means the following: On average, a US household with strong general beliefs about market fairness - which characterizes about half of US households - is willing to pay up to 27 percent of its disposable income to live in a just society. Positing that total disposable income of private households makes up 2/3 of GDP, the aggregate willingness to pay for justice equals 18 percent of US GDP.

The above computations extrapolate from the results based on the sub-sample containing respondents who had strong beliefs. According to our data, that subsample represents 48.26 percent of the households in the United States. The remaining 51.74 percent of the sample had weak and/or specific beliefs. Our theoretical model does not make predictions for these individuals. A priori, there seems to be nothing wrong in positing that these individuals have the same willingness to pay for justice as those in the other group. Preferences for justice have no evident relationship to beliefs about the fairness of market outcomes. These beliefs should be related to (indirect) preferences for governmental redistribution, not to (direct) preferences for justice. 
Constant progressivity. Table 2 displays estimates of $B_{f}$ and $A_{y}$ produced by assuming that the tax-transfer system has a constant coefficient of residual progression. As indicated by (9), in order to estimate $j$ one needs an estimate of the coefficient of residual progression, $r$. OECD (2005) presents estimates of that coefficient for several countries, including the US. The OECD estimates are not ideal for our purposes because they refer to wage earners only and to the year 2004. However, they are the best we could find. Based on that study, we posit that $r=0.85 .{ }^{10}$

Substituting the estimates of $B_{f}$ and $A_{y}$ from column 1 of Table 2 as well as $r=0.85$ into formula (9), one obtains an estimated value of $j=.176$. This number is reasonably close to the one obtained using the linear redistributive scheme in the sense that though smaller, it is still substantial.

Clearly, a willingness to pay for distributive justice of the order of 20 percent of disposable income is large. ${ }^{11}$ This is not an artifact of using the structural specification to recover the coefficients for computing $W / C$. Using the intermediate or the full specification (i.e. columns 2 and 3 in Tables 1 and 2) would produce even larger estimates. This is due to the fact that, according to (7) and (9), the value of distrib-

\footnotetext{
${ }^{10}$ See Table II.19 in OECD (2005). Accordingly, the coefficient of residual progression varies to some extent across households with different socio-economic composition. The value $r=0.85$ is found for married couples with two children, where one member of the couple earns the average wage and the other member earns $67 \%$ of the average wage. The coefficient of residual progression is found to be somewhat larger for households without children and somewhat lower for households with lower income.

${ }^{11}$ Interestingly, results from experimental dictator games point to similar orders of magnitude. In anonymous settings, dictators are willing to give up about $20 \%$ of the monetary payoff to the other player. In real US society, tips of $20 \%$ are not uncommon, e.g. in restaurants and for taxies.
} 
utive justice is proportional to the ratio of the coefficient of the beliefs variable to the coefficient of the income-dependent variable. Including control variables leaves the value of the coefficient on the beliefs variable almost unchanged while it decreases the value of the coefficient on the income-dependent variable, in absolute terms. Hence, the estimate of $j$ increases when control variables are included.

\section{Estimating the Value of Justice For Different types}

So far, our empirical investigation indicates that in the US there is a sizeable willingness to pay for living in a just society on average. We now ask whether this average magnitude mirrors homogeneous tastes or results from the aggregation of different tastes. Formally, we relax the assumption that individuals have the same utility function and empirically test whether different types within the population have different preferences for distributive justice.

5.1. Model. We extend the theoretical model of demand for redistribution of Sect. 2 as follows. Let individuals be described by a collection of dichotomous traits $k=1,2, \ldots K$. Variable $T_{k} \in\{0,1\}$ takes value 1 if and only if the individual has trait $k$. An individual's type is a vector of traits $\left(T_{1}, \ldots T_{K}\right)$. Types are assumed to affect preferences described by the utility function (1) according to

$$
\beta=\left(1+\sum_{k=1}^{K} \delta_{k} T_{k}\right) \Psi
$$


where $\Psi$ is a constant and $\delta_{k}, k=1,2, \ldots K$, captures the effect of having the corresponding trait $k$.

From Sect. 2 and (10), the willingness to pay for justice equals a fraction

$$
j=1-\exp \left(\frac{-2 \beta}{\alpha}\right)=1-\exp \left[\frac{-2 \Psi\left(1+\sum_{k=1}^{K} \delta_{k} T_{k}\right)}{\alpha}\right]
$$

of disposable income. Denote by $j_{k}$ the amount by which that fraction changes as a consequence of having trait $k$. By (11) we have:

$$
j_{k}=\left[1-\exp \left(\frac{-2 \Psi \delta_{k}}{\alpha}\right)\right] \exp \left[\frac{-2 \Psi}{\alpha}\left(1+\sum_{i \neq k} \delta_{i} T_{i}\right)\right]
$$

Notice that the willingness to pay induced by having a trait depends on the other traits of the individual. Provided that $2 \Psi / \alpha>0$, trait $k$ increases the willingness to pay for justice, i.e. $j_{k}>0$, if and only if $\delta_{k}>0$.

The method of gauging the trait-specific preferences $\delta_{k}$ depends on the redistributive scheme.

Case $C_{R}=y(1-t)+z$ :

Inserting (10) into (6) one obtains 
$\operatorname{Pr}[d=1 \mid y, f, x]=\operatorname{Pr}\left[\alpha \log \left(1-t+\frac{z}{y}\right)+\Psi(2-4 f)+\Psi(2-4 f) \sum_{k=1}^{K} \delta_{k} T_{k}+x^{\prime} \gamma+\varepsilon>0 \mid y, f, x\right]$

Notice that the vector $x^{\prime}$ may possibly include some or all the trait variables $T_{k}$, i.e. a trait may be associated with both a special taste for justice and an independent effect on the demand for redistribution.

Analogously to the model with identical preferences of Sect. 2, model (??) can be estimated by probit methods. Let $\widehat{b}_{f}=\sigma b_{f}$ and $\widehat{a}_{y}=\sigma a_{y}$ be the estimates of the coefficients on $f$ and $\log \left(1-t+\frac{z}{y}\right)$, respectively, where $b_{f}$ and $a_{y}$ are probit estimates and $\sigma$ is the (unknown) variance of the error term of the probit equation. Let $\widehat{b}_{k f}=\sigma b_{k f}$ be the estimate of the coefficient on $f T_{k}$. From $-4 \Psi=\sigma b_{f}$ and $-4 \Psi \delta_{k}=\sigma b_{k f}$, one obtains the crucial parameter for gauging the willingness to pay for justice associated with trait $k$ :

$$
\delta_{k}=\frac{b_{k f}}{b_{f}}
$$

Furthermore, by $\alpha=\sigma a_{y}$ one has

$$
\frac{2 \Psi}{\alpha}=\frac{-b_{f}}{2 a_{y}}
$$


which completes the data required in order to compute (11).

Case $C_{R}=s C_{N}^{r}$ :

From (8) we obtain

$\operatorname{Pr}[d=1 \mid y, f, x]=\operatorname{Pr}\left[\alpha \log (s)+(r-1) \alpha \log (y)+\Psi(2-4 f)+\Psi(2-4 f) \sum_{k=1}^{K} \delta_{k} T_{k}+x^{\prime} \gamma+\varepsilon>0 \mid y, f\right.$,

Let $\widehat{B}_{f}=\sigma B_{f}$ and $\widehat{A}_{y}=\sigma A_{y}$ be the estimates of the coefficients on $f$ and $\log (y)$, respectively, where $B_{f}$ and $A_{y}$ are probit estimates and $\sigma$ is the variance of the error term of the probit equation. Let $\widehat{B}_{k f}=\sigma B_{k f}$ be the estimate of the coefficient on $f T_{k}$. From $-4 \Psi=\sigma B_{f}$ and $-4 \Psi \delta_{k}=\sigma B_{k f}$ one obtains

$$
\delta_{k}=\frac{B_{k f}}{B_{f}}
$$

By $(r-1) \alpha=\sigma A_{y}$ one then has

$$
\frac{2 \Psi}{\alpha}=\frac{(1-r) B_{f}}{2 A_{y}}
$$

Hence, estimating the specific willingness to pay of a type merely requires regressing support for redistribution on a transformed income variable, a belief dummy, trait dummies, and the interactions between the belief and trait dummies. Having a given 
trait increases the relative willingness to pay for justice if and only if the estimated coefficients on the belief variable and the term interacting that particular trait have the same sign.

5.2. Results. Bringing this theoretical framework to the data ideally requires employing characteristics of respondents that are exogenous and uncorrelated with the key regressors beliefs and transformed income, so as to produce reliable coefficient estimates. In practice, these conditions may be hard to fulfill. With this caveat in mind, we produce rough estimates of the value of justice for different types. We present these estimates for traits that meet a minimal robustness requirement. More specifically, we require the interaction between the trait and the beliefs dummy - which is necessary for deducing $\delta_{k}$ - to be statistically significant in two specifications. The first specification adds the trait and the interaction term to the structural model that was presented in the first column of Tables 1 and 2. For each trait that had a significant interaction in this specification, we include it and its interaction, along with transformed income and the beliefs dummy, in a larger specification. We check that the interaction terms for each trait are also significant in this larger specification. Traits of the respondents that survive this selection procedure, i.e. have interaction terms that are statistically significant in both specifications, are considered to be associated with a distinctive taste for justice.

The traits of respondents that we tested using this method are the socio-demographic 
variables included in the intermediate specification that was presented in the second column of Tables 1 and 2. We collapsed age to a dummy for 40 years of age and older and education to a dummy for some college or more.

When we employ this selection procedure, we identify two traits that are associated with a distinctive taste for justice, namely race and education. The dummies for white and some college or more are the only ones to systematically have significant interactions at the five-percent level or better. This is true for both the linear and non-linear redistribution schemes.

Table 3 presents the larger specification that adds those two traits and their interactions with beliefs to the structural specification. Column 1 presents the results for the linear redistribution scheme, while column 2 presents the results for the scheme with constant progressivity. The table shows that the dummies for white and some college have significant interactions with the beliefs dummy in both redistribution schemes. As the coefficient on the belief variable has the expected negative sign, a trait increases the relative willingness to pay for justice if its interaction with the beliefs variable has a negative coefficient, and it decreases that willingness to pay if the coefficient is positive. Hence, both being white and having some higher education increase the relative willingness to pay for justice. We interpret this finding shortly.

[PLEASE INSERT TABLE 3 ABOUT HERE] 
The two traits associated with a distinctive taste for justice can be combined so as to define four different types. Using Equation (11), we calculate the value of justice for each of these types. These results are presented in Table 4. Under both redistributive schemes, the strongest preference for justice is associated with white respondents who have at least some college education; the willingness to pay of this type amounts to 41 percent of disposable income under the linear scheme and to nearly 28 percent under constant progressivity. The type with the lowest relative willingness to pay is a non-white respondent without college education; its willingness to pay equals 12 percent of disposable income under the linear scheme and less than 8 percent under constant progressivity. As the results in Table 4 clearly indicate, the concern for distributive justice is strongly affected by race and education.

\section{[PLEASE INSERT TABLE 4 ABOUT HERE]}

We now come to an interpretation of the finding that white respondents with some higher education exhibit a distinctively large relative willingness to pay for justice. A skeptic might point out that our estimation results might potentially be driven by a misspecification of the utility function: while we assumed that distributive justice is a normal good, it might be a luxury good. The effect that we documented above might thus reflect higher incomes on the part of white, educated individuals rather than a distinctive taste for justice. 
In order to scrutinize that conjecture, we have estimated a model based on the assumption that justice is a luxury good. That theoretical model and its estimation are presented in Appendix 2. Contrary to the above conjecture, we find similar results if we posit that justice is a luxury good. So, while it could be the case that the size of the differences in willingness to pay across types would be smaller than suggested by Table 4 if justice were a luxury, the conclusion that educated white individuals display a stronger concern for justice remains valid.

In order to interpret our findings, recall that distributive justice was defined at the outset as distribution according to desert. While we have supposed that everybody views justice in that way, some individuals might instead evaluate the fairness of the income distribution according to the justice principles of need or simple equality. Our results suggest that those individuals are likely to be non-educated and non-white.

Respondents who are educated might put special emphasis on distribution according to desert because they have already expended much effort in order to increase their human capital and want to reap the gains from their investment. Respondents who are white might display a special taste for distribution according to effort because accumulating human capital and selling its services might be less costly for them than for some minority groups. Members of minorities who set out to accumulate human capital might have a hard time because they live in communities where group norms discourage one from achievement in school and the workplace. Furthermore, for mi- 
nority members who succeed in terms of formal education, selling their services to employers may entail costly signalling in order to overcome negative stereotypes. ${ }^{12}$

5.3. The respective role of preferences, beliefs and income. The theoretical model that we have brought to the data in this section has individual attitudes towards governmental redistribution of income determined by pre-fisc income, beliefs about the fairness of market outcomes and type-specific tastes for distributive justice. Which factor is the most important determinant of support for and opposition to redistribution?

In order to address this issue, we compute predicted probabilities of support for redistribution on the basis of the probit regressions presented in Table 3 . We consider sixteen hypothetical respondents that can be obtained by combining the three dummy variables - namely beliefs about market fairness, white, and some college or more - and two income levels, namely median income and five times the median income. The associated predicted probabilities, under both the linear and the nonlinear redistribution scheme, are shown in Table 5.

\section{[PLEASE INSERT TABLE 5 ABOUT HERE]}

As shown by Table 5, beliefs are a much more powerful motive for support for

\footnotetext{
${ }^{12}$ See Bénabou and Tirole (2006) and Corneo and Jeanne (2007) for recent theoretical work on the management of beliefs and the choice of value systems.
} 
redistribution than pre-fisc income. Taking the unweighted average over all hypothetical respondents that believe the market is unfair under both redistribution schemes, shows that the predicted probability of supporting redistribution is almost 58 percent. The corresponding average probability of supporting redistribution for those who believe that the market is fair is just 32 percent. Hence, a switch in beliefs leads to a twenty-six percentage point change in the probability of supporting redistribution.

The pecuniary effect is much smaller. The average probability of supporting redistribution for someone with median pre-fisc income is almost 50 percent. Multiplying that income by five merely diminishes that probability by less than ten percentage points. Hence, even a very large income difference makes only a moderate difference in support for governmental redistribution.

The maximal difference in the taste for justice - i.e. for distribution according to desert - obtains if one compares white respondents with some college or more to non-white respondents without college education. The former respondents have a much higher relative willingness to pay for justice than the latter. Taking the unweighted average of the predicted probabilities of supporting redistribution for the first group shows that white respondents with some higher education are in favor of redistribution with a probability of about 38 percent. The corresponding probability for non-white respondents without higher education amounts to about 52 percent. Therefore, even the maximal difference in tastes for justice produces a substantially 
smaller difference in attitudes towards redistribution compared to what is triggered by a difference in beliefs of market fairness. ${ }^{13}$

\section{Conclusion}

This paper developed a simple theoretical model that can be empirically implemented to estimate the monetary value of distributive justice, defined as distribution according to desert, and to uncover group-specific preferences for it. As an application, we have estimated the value of distributive justice in the United States.

Our empirical exercise has delivered several insights into the concerns for distributive justice and the factors that drive demand for income redistribution. First, our estimates indicate that the willingness to pay for distributive justice in the United States is substantial. While our reference estimate of about 20 percent of disposable income may be exaggerated by data problems and a strongly simplified theoretical framework, our analysis clearly supports the claim that people's concern for justice is one that is sizeable in monetary terms. This is one more reason, and a specifically economic one, why economists should be interested in distributive justice.

Second, preferences for a just distribution are not homogeneous: a cleavage along the lines of race and education seems to exist in the US. We have found that white

\footnotetext{
${ }^{13}$ According to the model estimated in this section, if a respondent believes that the market is fair, being white and having some college education increase opposition to governmental redistribution. Therefore, a stronger concern for justice appears to diminish the probability of supporting governmental redistribution. Notice that in the sample used for our regressions, about $60 \%$ of respondents believe that the market is fair, i.e. that being poor is caused by lack of effort and being rich is caused by strong effort.
} 
individuals with some higher education have a markedly larger willingness to pay for it than the rest of the population. This difference is not due to distributive justice being a luxury good, but reflects different tastes. We have conjectured that noneducated minorities may subscribe to a different notion of distributive justice, one that stresses needs and simple equality more and desert less than the one endorsed by the educated white.

Third, demand for governmental reduction of income inequality is driven by prefisc income, beliefs in the fairness of the market system, and preferences for distributive justice to different extents. We have computed how predicted probabilities of supporting redistribution respond to those three determinants and found that the factor that drives demand for redistribution in the US most is the belief that market outcomes are driven by luck or circumstances beyond one's control rather than one's effort.

Our estimates should be interpreted with caution. The theoretical model on which they are based is a very stylized one, which defines distributive justice as a dichotomous variable. While this is an acceptable first step, in reality perceptions of distributive justice are more like a continuous variable. Extending the current model to account for such perceptions would be worthwhile. With respect to the empirical measures of attitudes and beliefs, those available were far from ideal. It would be very helpful to have survey questions that are less vulnerable to multiple interpretations 
and allow for a finer grid of measurement.

We have put forward the conjecture that endorsed notions of distributive justice might be heterogeneous: some subgroups might place a distinctive emphasis on needs and simple equality, rather than desert. A next step in this line of research would be to scrutinize that conjecture, both on theoretical and empirical grounds. Maybe, a method could be developed to estimate the willingness to pay for an egalitarian or needs-based income distribution.

Finally, a fascinating task would be to bring the approach developed in this paper to an international data set. One would be interested in assessing how the relative willingness to pay for distributive justice varies across countries and which notions of justice are associated with different cultures. We leave this task to future research. 


\section{[PLEASE INSERT TABLES A1 AND A2 ABOUT HERE]}

\section{Appendix A: Estimates of the basic model using an alternative measure of beliefs}

In our main analysis presented above we use a measure of beliefs that was available for only about half of the sample. In this appendix, we replicate the analysis using a different measure of beliefs that is available for the vast majority of respondents. This second measure of beliefs is the following survey question: "Do you think the economic system in the United States is (read and rotate 1-2)? 1) Basically fair, since all Americans have an equal opportunity to succeed OR 2) Basically unfair, since all Americans do not have an equal opportunity to succeed 3) Don't know." We refer to this measure as ECONFAIR. Out of the whole nationally representative sample, 68.00 percent of the respondents said the economic system is "basically fair", 29.41 percent said "basically unfair", and only 2.59 percent said "don't know" or did not respond. We code "basically unfair" as zero and "basically fair" as one. While this measure has the advantage of being available for over 97 percent of our sample, it has the disadvantage of being more ambiguous. While we would like to know whether or not respondents believe the market system to be fair, ECONFAIR asks about the fairness of the economic system.

Tables A3 and A4 replicate Tables 1 and 2, except that they use ECONFAIR to measure beliefs about market fairness. As shown by Table A3, the belief that 
the economic system is fair has a negative and highly significant effect on support for redistribution in every specification. The table shows that the coefficient on the belief measure is not affected very much by specification changes. The transformed income variable has a highly significant effect on support for redistribution in the structural and intermediate specifications presented in columns 1 and 2, but not in the full specification presented in column 3. The transformed variable is inversely related to income, so income itself has a negative effect on support for redistribution, as expected. However, the coefficient on transformed income is quite sensitive to specification changes. Thus, for the purpose of estimating the coefficient on transformed income, the common practice of including as many control variables as possible is clearly inappropriate. The results are similar in the case of nonlinear redistribution, as shown by Table A4. The coefficients on the beliefs about market fairness are very similar to those in Table A3 and as before, are not sensitive to specification changes. The coefficient on the log of income has a highly significant negative effect in columns 1 and 2, and a marginally significant negative effect in column 3 . As before, the coefficient on the log of income is very sensitive to the specification. Given these findings, the full specification is clearly inappropriate.

\section{[PLEASE INSERT TABLES A3 AND A4 ABOUT HERE]}

Thus, as before, we use the structural specification to calculate our baseline esti- 
mates of the value of justice. In the case of linear redistribution, $j=.260$. In the case of redistribution with constant progressivity redistribution, $j=.167$.

Finally, we replicated Table 3 using ECONFAIR to measure beliefs about market fairness instead of the measure constructed from WHYPOOR and WHYRICH (unreported). The interaction terms are in the same direction, although the interaction between Some college or more and Belief that economic system is fair is not significant in either redistribution scheme (the p-values are roughly 0.2 in both cases). The interaction between White and Belief that economic system is fair is again significant (at the five-percent level) in both redistribution schemes. Thus, while the evidence is slightly weaker using ECONFAIR, we again find heterogeneity in the value of justice according to types. 
Appendix B: Model with heterogeneous preferences and justice as a luxury good

Assume a Stone-Geary formulation of the utility function,

$$
U=\alpha \log (C-m)+\beta J
$$

where $m>0$ captures some minimal consumption level. The willingness to pay for justice is implicitly defined by

$$
\alpha \log (C-m-W)+\beta=\alpha \log (C-m)-\beta,
$$

which gives

$$
\frac{W}{C}=\left[1-\exp \left(\frac{-2 \beta}{\alpha}\right)\right]\left(1-\frac{m}{C}\right)
$$

Hence, the relative willingness to pay for justice increases with income.

Suppose that types affect preferences according to (10). Under a linear redistributive scheme, we obtain

$\operatorname{Pr}[d=1 \mid y, f, x]=\operatorname{Pr}\left[\alpha \log \left[\frac{y(1-t)+z-m}{y-m}\right]+\Psi(2-4 f)+\Psi(2-4 f) \sum_{k=1}^{K} \delta_{k} T_{k}+x^{\prime} \gamma+\varepsilon>0 \mid y, f, x\right]$ 
Estimating this relationship requires one to choose a numerical value for $m$. In order to avoid wasting observations, we set $m$ equal to half of the minimal pre-fisc income observed in our data set. This amounts to $m=3,750 .{ }^{14}$

Table A5 reports the results from estimating (14) using the traits white and some college. Similarly to Table 3, both interaction terms are statistically significant. Hence, those two traits are found to be associated with a distinctive taste for justice also under the assumption that justice is a luxury good.

[PLEASE INSERT TABLE A5 ABOUT HERE]

\footnotetext{
${ }^{14}$ If we assume a redistributive scheme with constant progressivity, i.e. $C_{R}=s C_{N}^{r}$, the transformed-income variable entering the probit model entails the coefficient $s$. Since we have no knowledge of that coefficient, we cannot estimate the model under that redistributive scheme.
} 


\section{References}

Alesina, A. and G.-M. Angeletos, 2005, Fairness and redistribution, American Economic Review 95, 960-980.

Alesina, A. and E. La Ferrara, 2005, Preferences for redistribution in the land of opportunities, Journal of Public Economics 89, 897-931.

Bénabou, R. and J. Tirole, 2006, Identity, Dignity and Taboos: Beliefs as Assets, mimeo, Princeton University.

Corneo, G., 2001, Inequality and the state: Comparing US and German preferences, Annales d'Economie et de Statistique 63-64, 283-296.

Corneo, G. and C. Fong, 2005, What's the monetary value of distributive justice?, CEPR DP No. 5227.

Corneo, G. and H.-P. Grüner, 2002, Individual preferences for political redistribution, Journal of Public Economics 83, 83-107.

Corneo, G. and O. Jeanne, 2007, A theory of tolerance, CESifo WP No. 1941.

Fong, C., 2001, Social preferences, self-interest, and the demand for redistribution, Journal of Public Economics 82, 225-246. 
Fong, C. 2005, Which beliefs matter for redistributive politics? Target-specific versus general beliefs about the causes of income, mimeo.

Gallup Organization, 1998, Haves and Have-Nots: Perceptions of Fairness and Opportunity, Gallup Organization.

Osberg, L. and T. Smeeding, 2006, "Fair" inequality? Attitudes toward pay differentials: The United States in comparative perspective, American Sociological Review 71, 450-473.

Piketty, T., 1995, Social mobility and redistributive politics, Quarterly Journal of Economics 110, 551-585.

OECD, 2005, Taxing Wages, Paris.

Roemer, J. and fourteen coauthors, 2003, To what extent do fiscal regimes equalize opportunities for income acquisition among citizens? Journal of Public Economics $87,539-565$.

Schokkaert, E., 1998, Mr. Fairmind is post-welfarist: Opinions on distributive justice, Discussion Paper 98.09, Center for Economic Studies, Katholieke Universiteit Leuven.

Thurow, L., 1971, The income distribution as a pure public good, Quarterly Journal of Economics 85, 327-336. 
Table 1. Probit regressions predicting support for redistribution assuming a linear redistributive scheme.

\begin{tabular}{|c|c|c|c|}
\hline & $(1)$ & $(2)$ & (3) \\
\hline $\begin{array}{l}\text { Belief that income is caused by } \\
\text { effort }\end{array}$ & $\begin{array}{l}-0.811 * * * \\
(0.063)\end{array}$ & $\begin{array}{l}-0.823 * * * \\
(0.066)\end{array}$ & $\begin{array}{l}-0.800^{* * *} \\
(0.071)\end{array}$ \\
\hline Transformed income variable & $\begin{array}{l}1.290 * * * \\
(0.22)\end{array}$ & $\begin{array}{l}0.860 * * * \\
(0.26)\end{array}$ & $\begin{array}{l}0.511 \\
(0.33)\end{array}$ \\
\hline White & & $\begin{array}{l}-0.051 \\
(0.11)\end{array}$ & $\begin{array}{l}-0.098 \\
(0.12)\end{array}$ \\
\hline Male & & $\begin{array}{l}-0.103 \\
(0.15)\end{array}$ & $\begin{array}{l}-0.102 \\
(0.16)\end{array}$ \\
\hline White*male & & $\begin{array}{l}-0.240 \\
(0.16)\end{array}$ & $\begin{array}{l}-0.290^{*} \\
(0.17)\end{array}$ \\
\hline Age & & $\begin{array}{l}-0.011 \\
(0.025)\end{array}$ & $\begin{array}{l}-0.017 \\
(0.027)\end{array}$ \\
\hline Age squared & & $\begin{array}{l}-5.6 \mathrm{E}-5 \\
(2.3 \mathrm{E}-4)\end{array}$ & $\begin{array}{l}6.8 \mathrm{E}-6 \\
(2.4 \mathrm{E}-4)\end{array}$ \\
\hline High school graduate & & $\begin{array}{l}-0.040 \\
(0.12)\end{array}$ & $\begin{array}{l}0.043 \\
(0.13)\end{array}$ \\
\hline $\begin{array}{l}\text { Technical, trade, or business } \\
\text { degree after high school }\end{array}$ & & $\begin{array}{l}0.087 \\
(0.17)\end{array}$ & $\begin{array}{l}0.155 \\
(0.18)\end{array}$ \\
\hline Some college & & $\begin{array}{l}-0.278^{* *} \\
(0.12)\end{array}$ & $\begin{array}{l}-0.165 \\
(0.13)\end{array}$ \\
\hline College degree & & $\begin{array}{l}-0.352 * * * \\
(0.13)\end{array}$ & $\begin{array}{l}-0.217 \\
(0.15)\end{array}$ \\
\hline $\begin{array}{l}\text { Some post-graduate education } \\
\text { or more }\end{array}$ & & $\begin{array}{l}-0.322^{* *} \\
(0.13)\end{array}$ & $\begin{array}{l}-0.162 \\
(0.15)\end{array}$ \\
\hline Children under 18 living at home & & $\begin{array}{l}-0.031 \\
(0.077)\end{array}$ & $\begin{array}{l}-0.097 \\
(0.084)\end{array}$ \\
\hline Married & & $\begin{array}{l}-0.015 \\
(0.073)\end{array}$ & $\begin{array}{l}-0.005 \\
(0.079)\end{array}$ \\
\hline Suburban & & $\begin{array}{l}-0.162 * * \\
(0.074)\end{array}$ & $\begin{array}{l}-0.195^{* *} \\
(0.079)\end{array}$ \\
\hline Rural & & $\begin{array}{l}0.0262 \\
(0.088)\end{array}$ & $\begin{array}{l}-0.006 \\
(0.095)\end{array}$ \\
\hline Observations & 2225 & 2190 & 2061 \\
\hline Wald chi-square & 227.1 & 294.9 & 387.3 \\
\hline
\end{tabular}

Numbers shown are coefficients (robust standard errors in parentheses). ${ }^{*}, * *$, and $* * *$ indicate significance at the ten-, five-, and one-percent levels, respectively. All equations include a constant. Equation in column 2 also includes four age group dummies. Equation in column 3 also includes four age group dummies, 75 occupation dummies, ten asset dummies, three dummies for not having had enough money to buy food clothing and medical care in the last year, three dummies for subjective financial worries and dummies for being unemployed, employed part-time, a home owner and a union member. 
Table 2. Probit regressions predicting support for redistribution assuming a redistributive scheme with constant progressivity.

\begin{tabular}{|c|c|c|c|}
\hline & (1) & $(2)$ & (3) \\
\hline $\begin{array}{l}\text { Belief that income is caused by } \\
\text { Effort }\end{array}$ & $\begin{array}{l}-0.800 * * * \\
(0.063)\end{array}$ & $\begin{array}{l}-0.812 * * * \\
(0.066)\end{array}$ & $\begin{array}{l}-0.798 * * * \\
(0.072)\end{array}$ \\
\hline Log income & $\begin{array}{l}-0.309 * * * \\
(0.043)\end{array}$ & $\begin{array}{l}-0.221 * * * \\
(0.051)\end{array}$ & $\begin{array}{l}-0.131 * \\
(0.069)\end{array}$ \\
\hline White & & $\begin{array}{l}-0.045 \\
(0.11)\end{array}$ & $\begin{array}{l}-0.096 \\
(0.12)\end{array}$ \\
\hline Male & & $\begin{array}{l}-0.100 \\
(0.15)\end{array}$ & $\begin{array}{l}-0.101 \\
(0.16)\end{array}$ \\
\hline White*male & & $\begin{array}{l}-0.240 \\
(0.16)\end{array}$ & $\begin{array}{l}-0.293^{*} \\
(0.17)\end{array}$ \\
\hline Age & & $\begin{array}{l}-0.012 \\
(0.025)\end{array}$ & $\begin{array}{l}-0.017 \\
(0.027)\end{array}$ \\
\hline Age squared & & $\begin{array}{l}-5.0 \mathrm{E}-5 \\
(2.3 \mathrm{E}-4)\end{array}$ & $\begin{array}{l}4.8 \mathrm{E}-6 \\
(2.4 \mathrm{E}-4)\end{array}$ \\
\hline High school graduate & & $\begin{array}{l}-0.032 \\
(0.12)\end{array}$ & $\begin{array}{l}0.043 \\
(0.13)\end{array}$ \\
\hline $\begin{array}{l}\text { Technical, trade, or business } \\
\text { degree after high school }\end{array}$ & & $\begin{array}{l}0.099 \\
(0.17)\end{array}$ & $\begin{array}{l}0.156 \\
(0.18)\end{array}$ \\
\hline Some college & & $\begin{array}{l}-0.253^{* *} \\
(0.12)\end{array}$ & $\begin{array}{l}-0.159 \\
(0.13)\end{array}$ \\
\hline College degree & & $\begin{array}{l}-0.315^{* *} \\
(0.13)\end{array}$ & $\begin{array}{l}-0.208 \\
(0.15)\end{array}$ \\
\hline $\begin{array}{l}\text { Some post-graduate education } \\
\text { or more }\end{array}$ & & $\begin{array}{l}-0.263^{* *} \\
(0.13)\end{array}$ & $\begin{array}{l}-0.149 \\
(0.15)\end{array}$ \\
\hline $\begin{array}{l}\text { Children under } 18 \text { living at } \\
\text { home }\end{array}$ & & $\begin{array}{l}-0.032 \\
(0.077)\end{array}$ & $\begin{array}{l}-0.097 \\
(0.084)\end{array}$ \\
\hline Married & & $\begin{array}{l}0.002 \\
(0.073)\end{array}$ & $\begin{array}{l}2.3 \mathrm{E}-4 \\
(0.079)\end{array}$ \\
\hline Suburban & & $\begin{array}{l}-0.155^{* *} \\
(0.074)\end{array}$ & $\begin{array}{l}-0.192 * * \\
(0.079)\end{array}$ \\
\hline Rural & & $\begin{array}{l}0.018 \\
(0.088)\end{array}$ & $\begin{array}{l}-0.010 \\
(0.095)\end{array}$ \\
\hline Observations & 2225 & 2190 & 2061 \\
\hline Wald chi-square & 245.2 & 304.4 & 390.3 \\
\hline
\end{tabular}

See notes to Table 1 . 
Table 3. Probit regressions predicting support for redistribution allowing for type-specific preferences in the linear and constant progressivity redistributive schemes.

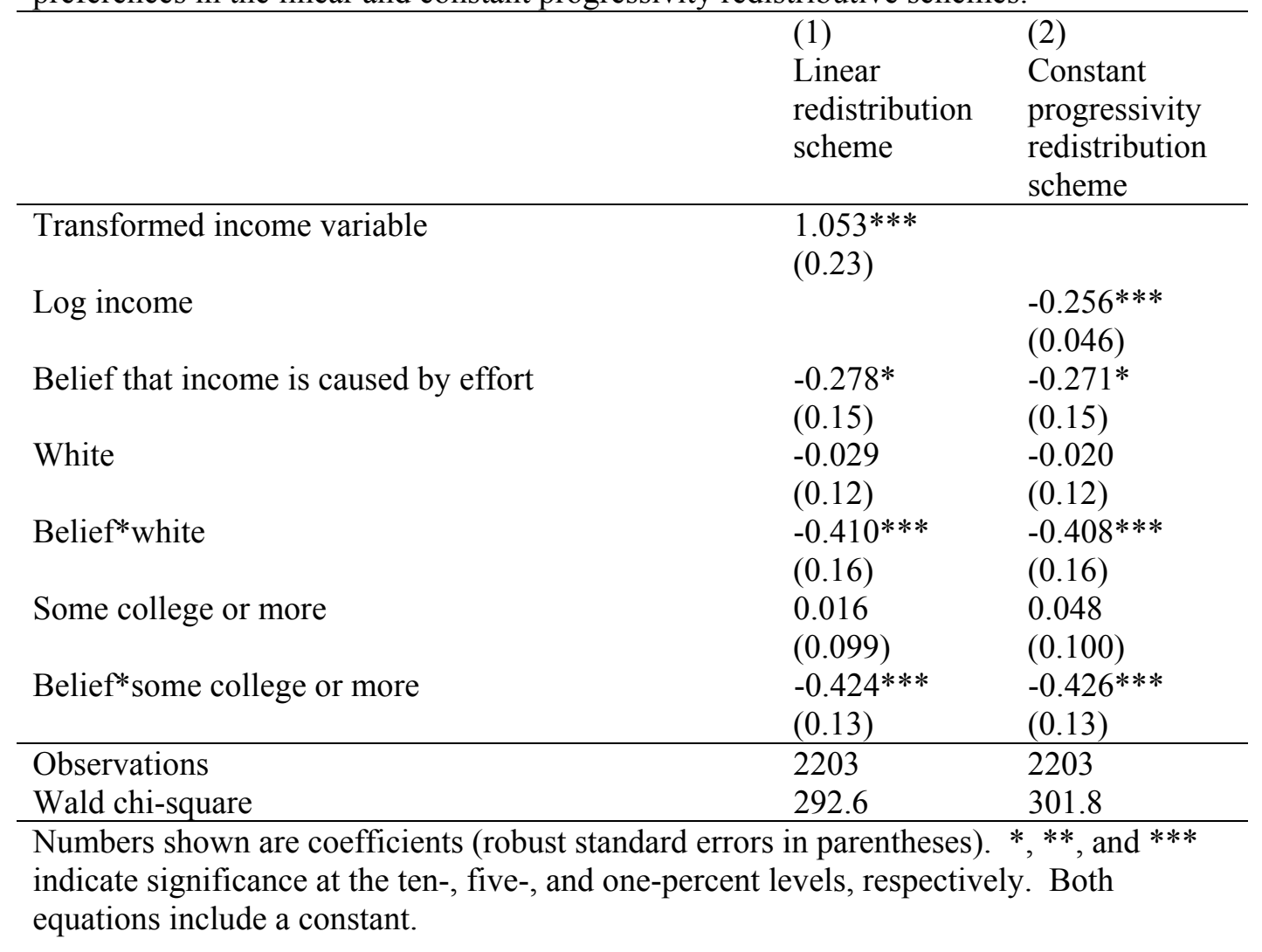


Table 4. Willingness to pay for justice as a fraction of disposable income for four types. White

Non-white

PANEL A. Linear redistribution scheme

Some college or more

No college

.410

.284

.279

.124

PANEL B. Constant progressivity redistribution scheme

Some college or more

.277

.185

No college

.181

.077 
Table 5. Predicted probabilities of supporting redistribution.

\begin{tabular}{lll}
\multicolumn{2}{c}{ Believes market is fair } & Believes market is unfair \\
White & Non-white
\end{tabular}

PANEL A. Individuals with median household income under linear redistribution scheme.

$\begin{array}{lllll}\text { Some college or more } & .213 & .360 & .624 & .635\end{array}$

No college

$.349 \quad .520$

.618

.629

PANEL B. Individuals with five times the median household income under linear redistribution scheme.

$\begin{array}{lllll}\text { Some college or more } & .175 & .311 & .571 & .582 \\ \text { No college } & .300 & .466 & .565 & .576\end{array}$

PANEL C. Individuals with median household income under constant progressivity redistribution scheme

Some college or more

No college

$\begin{array}{llll}.228 & .376 & .641 & .648 \\ .357 & .524 & .623 & .630\end{array}$

PANEL D. Individuals with five times the median household income under constant progressivity redistribution scheme

\begin{tabular}{lllll}
\hline Some college or more & .124 & .233 & .480 & .488 \\
No college & .218 & .363 & .461 & .469 \\
\hline
\end{tabular}


Table A1. Exact wording of and responses to measures of dependent variable and beliefs about fairness of market outcomes.

Dependent Variable: "People feel differently about how far a government should go. Here is a phrase which some people believe in and some don't. Do you think our government should or should not redistribute wealth by heavy taxes on the rich?"

"Should" (44.69\%)

"Should not" (51.52\%)

"Don't know " $(2.93 \%)$

Non-response $(0.86 \%)$

WHYPOOR: "Just your opinion, which is more often to blame if a person is poor - lack of effort on his or her part, or circumstances beyond his or her control?"

"Luck or circumstances beyond his/her control" (40.59\%)

"Both" (13.95\%)

"Lack of effort" $(42.80 \%)$

"Don't know" (1.84\%)

Non-response $(.82 \%)$

WHYRICH: "Just your opinion, which is more often to blame if a person is rich -strong effort to succeed on his or her part, or luck or circumstances beyond his or her control?"

"Luck or circumstances beyond his/her control" (31.88\%)

"Both" (11.34\%)

"Strong effort" (53.22\%)

"Don't know" (2.61\%)

Non-response $(0.95 \%)$

ECONFAIR: "Do you think the economic system in the United States is (read and rotate 1-2)?"

"1) Basically fair, since all Americans have an equal opportunity to succeed OR" $(68.00 \%)$

“2) Basically unfair, since all Americans do not have an equal opportunity to succeed" $(29.41 \%)$

"3) Don't know." (1.91\%)

Non-response $(0.68 \%)$

Percentages shown are estimated nationally representative proportions using sample weights.

$\mathrm{N}=5001$ (including non-response). 
Table A2. Summary statistics for selected regressors. ${ }^{\text {a }}$

\begin{tabular}{|c|c|c|c|}
\hline & $\mathrm{N}$ & $\begin{array}{c}\text { Est. } \\
\text { Mean }^{\text {b }}\end{array}$ & S.E. \\
\hline \multicolumn{4}{|l|}{ Continuous Variables } \\
\hline $\begin{array}{l}\text { Income (Constructed by representing each of nine income categories by } \\
\text { their estimated medians. Category medians are estimated with data from } \\
\text { the concurrent CPS March Supplement.) }\end{array}$ & 4571 & 46772.19 & 553.258 \\
\hline Age & 4925 & 44.85 & 0.282 \\
\hline Age squared & 4925 & 2311.82 & 28.437 \\
\hline \multicolumn{4}{|l|}{ Dummy Variables } \\
\hline White & 4899 & 0.809 & 0.006 \\
\hline Male & 4998 & 0.476 & 0.008 \\
\hline Age group 2 (30-39 yrs.) & 4925 & 0.222 & 0.006 \\
\hline Age group 3 (40-49 yrs.) & 4925 & 0.204 & 0.006 \\
\hline Age group 4 (50-64 yrs.) & 4925 & 0.189 & 0.006 \\
\hline Age group 5 (65-99 yrs.) & 4925 & 0.165 & 0.006 \\
\hline High school graduate & 4959 & 0.279 & 0.007 \\
\hline Technical, trade, or business degree after high school & 4959 & 0.053 & 0.003 \\
\hline Some college & 4959 & 0.269 & 0.007 \\
\hline College degree & 4959 & 0.110 & 0.004 \\
\hline Some post-graduate education or more & 4959 & 0.118 & 0.004 \\
\hline Child under 18 living at home & 4967 & 0.388 & 0.007 \\
\hline Married & 4961 & 0.541 & 0.008 \\
\hline Suburban & 5001 & 0.477 & 0.008 \\
\hline Rural & 5001 & 0.228 & 0.006 \\
\hline In last year, did not have enough money to buy clothing family needed & 4988 & 0.174 & 0.006 \\
\hline In last year, did not have enough money to buy food family needed & 4989 & 0.110 & 0.005 \\
\hline In last year, did not have enough money to pay for medical care & 4980 & 0.218 & 0.006 \\
\hline Worries that income will not meet bills: most of the time & 4971 & 0.444 & 0.008 \\
\hline Worries that income will not meet bills: some of the time & 4971 & 0.119 & 0.005 \\
\hline Worries that income will not meet bills: almost never & 4971 & 0.094 & 0.005 \\
\hline Union member & 4966 & 0.108 & 0.005 \\
\hline Employed part-time & 4961 & 0.129 & 0.005 \\
\hline Not employed & 4961 & 0.307 & 0.007 \\
\hline Non-home assets $>\$ 0<\$ 1000$ & 4453 & 0.029 & 0.003 \\
\hline Non-home assets $\geq \$ 1000<\$ 5000$ & 4453 & 0.057 & 0.004 \\
\hline Non-home assets $\geq \$ 5000<\$ 10,000$ & 4453 & 0.067 & 0.004 \\
\hline Non-home assets $\geq \$ 10,000<\$ 30,000$ & 4453 & 0.162 & 0.006 \\
\hline Non-home assets $\geq \$ 30,000<\$ 50,000$ & 4453 & 0.109 & 0.005 \\
\hline Non-home assets $\geq \$ 50,000<\$ 75,000$ & 4453 & 0.068 & 0.004 \\
\hline Non-home assets $\geq \$ 75,000<\$ 100,000$ & 4453 & 0.047 & 0.003 \\
\hline Non-home assets $\geq \$ 100,000<\$ 250,000$ & 4453 & 0.079 & 0.004 \\
\hline Non-home assets $\geq \$ 250,000<\$ 500,000$ & 4453 & 0.032 & 0.003 \\
\hline Non-home assets $>\$ 500,000$ & 4453 & 0.032 & 0.003 \\
\hline
\end{tabular}

${ }^{\mathrm{a}}$ The full specification includes 75 occupation dummies that are not summarized in this table. ${ }^{\mathrm{b}}$ Means are estimated from the nationally representative weighted sample. 
Table A3. Probit regressions predicting support for redistribution assuming a linear redistributive scheme.

\begin{tabular}{|c|c|c|c|}
\hline & $(1)$ & $(2)$ & (3) \\
\hline $\begin{array}{l}\text { Belief that economic system is } \\
\text { fair }\end{array}$ & $\begin{array}{l}-0.687 * * * \\
(0.047)\end{array}$ & $\begin{array}{l}-0.619 * * * \\
(0.049)\end{array}$ & $\begin{array}{l}-0.615 * * * \\
(0.053)\end{array}$ \\
\hline Transformed income variable & $\begin{array}{l}1.140 * * * \\
(0.15)\end{array}$ & $\begin{array}{l}0.699 * * * \\
(0.17)\end{array}$ & $\begin{array}{l}0.261 \\
(0.22)\end{array}$ \\
\hline White & & $\begin{array}{l}-0.113 \\
(0.079)\end{array}$ & $\begin{array}{l}-0.149^{*} \\
(0.083)\end{array}$ \\
\hline Male & & $\begin{array}{l}-0.156 \\
(0.10)\end{array}$ & $\begin{array}{l}-0.187^{*} \\
(0.11)\end{array}$ \\
\hline White*male & & $\begin{array}{l}-0.099 \\
(0.12)\end{array}$ & $\begin{array}{l}-0.092 \\
(0.12)\end{array}$ \\
\hline Age & & $\begin{array}{l}4.7 \mathrm{E}-4 \\
(0.017)\end{array}$ & $\begin{array}{l}-0.008 \\
(0.018)\end{array}$ \\
\hline Age squared & & $\begin{array}{l}-7.0 \mathrm{E}-5 \\
(1.5 \mathrm{E}-5)\end{array}$ & $\begin{array}{l}-6.3 \mathrm{E}-6 \\
(1.6 \mathrm{E}-4)\end{array}$ \\
\hline High school graduate & & $\begin{array}{l}-0.147^{*} \\
(0.080)\end{array}$ & $\begin{array}{l}-0.075 \\
(0.084)\end{array}$ \\
\hline $\begin{array}{l}\text { Technical, trade, or business } \\
\text { degree after high school }\end{array}$ & & $\begin{array}{l}-0.079 \\
(0.11)\end{array}$ & $\begin{array}{l}0.034 \\
(0.12)\end{array}$ \\
\hline Some college & & $\begin{array}{l}-0.425 * * * \\
(0.082)\end{array}$ & $\begin{array}{l}-0.310^{* * *} \\
(0.089)\end{array}$ \\
\hline College degree & & $\begin{array}{l}-0.372 * * * \\
(0.092)\end{array}$ & $\begin{array}{l}-0.213^{* *} \\
(0.10)\end{array}$ \\
\hline $\begin{array}{l}\text { Some post-graduate education or } \\
\text { more }\end{array}$ & & $\begin{array}{l}-0.378^{* * * *} \\
(0.090)\end{array}$ & $\begin{array}{l}-0.218 * * \\
(0.10)\end{array}$ \\
\hline Children under 18 living at home & & $\begin{array}{l}-0.011 \\
(0.053)\end{array}$ & $\begin{array}{l}-0.049 \\
(0.057)\end{array}$ \\
\hline Married & & $\begin{array}{l}-0.062 \\
(0.051)\end{array}$ & $\begin{array}{l}-0.083 \\
(0.055)\end{array}$ \\
\hline Suburban & & $\begin{array}{l}-0.038 \\
(0.052)\end{array}$ & $\begin{array}{l}-0.041 \\
(0.055)\end{array}$ \\
\hline Rural & & $\begin{array}{l}0.070 \\
(0.061)\end{array}$ & $\begin{array}{l}0.074 \\
(0.065)\end{array}$ \\
\hline Observations & 4362 & 4292 & 4037 \\
\hline Wald chi-square & 298.3 & 382.3 & 519.3 \\
\hline
\end{tabular}

See notes to Table 1 . 
Table A4. Probit regressions predicting support for redistribution assuming a redistributive scheme with constant progressivity.

\begin{tabular}{|c|c|c|c|}
\hline & (1) & $(2)$ & (3) \\
\hline $\begin{array}{l}\text { Belief that economic system is } \\
\text { fair }\end{array}$ & $\begin{array}{l}-0.673 * * * \\
(0.047)\end{array}$ & $\begin{array}{l}-0.609 * * * \\
(0.049)\end{array}$ & $\begin{array}{l}-0.613 * * * \\
(0.053)\end{array}$ \\
\hline Log income & $\begin{array}{l}-0.276^{* * *} \\
(0.029)\end{array}$ & $\begin{array}{l}-0.194 * * * \\
(0.036)\end{array}$ & $\begin{array}{l}-0.088^{*} \\
(0.048)\end{array}$ \\
\hline White & & $\begin{array}{l}-0.106 \\
(0.079)\end{array}$ & $\begin{array}{l}-0.147^{*} \\
(0.083)\end{array}$ \\
\hline Male & & $\begin{array}{l}-0.150 \\
(0.10)\end{array}$ & $\begin{array}{l}-0.185^{*} \\
(0.11)\end{array}$ \\
\hline White*male & & $\begin{array}{l}-0.104 \\
(0.11)\end{array}$ & $\begin{array}{l}-0.096 \\
(0.12)\end{array}$ \\
\hline Age & & $\begin{array}{l}-8.5 \mathrm{E}-4 \\
(0.017)\end{array}$ & $\begin{array}{l}-0.008 \\
(0.018)\end{array}$ \\
\hline Age squared & & $\begin{array}{l}-6.3 \mathrm{E}-5 \\
(1.5 \mathrm{E}-4)\end{array}$ & $\begin{array}{l}-3.8 \mathrm{E}-6 \\
(1.6 \mathrm{E}-4)\end{array}$ \\
\hline High school graduate & & $\begin{array}{l}-0.140^{*} \\
(0.079)\end{array}$ & $\begin{array}{l}-0.074 \\
(0.084)\end{array}$ \\
\hline $\begin{array}{l}\text { Technical, trade, or business } \\
\text { degree after high school }\end{array}$ & & $\begin{array}{l}-0.070 \\
(0.11)\end{array}$ & $\begin{array}{l}0.033 \\
(0.12)\end{array}$ \\
\hline Some college & & $\begin{array}{l}-0.401 * * * \\
(0.082)\end{array}$ & $\begin{array}{l}-0.306^{* * *} \\
(0.089)\end{array}$ \\
\hline College degree & & $\begin{array}{l}-0.331 * * * \\
(0.092)\end{array}$ & $\begin{array}{l}-0.204^{* *} \\
(0.10)\end{array}$ \\
\hline $\begin{array}{l}\text { Some post-graduate education or } \\
\text { more }\end{array}$ & & $\begin{array}{l}-0.318^{* * * *} \\
(0.091)\end{array}$ & $\begin{array}{l}-0.204^{*} \\
(0.11)\end{array}$ \\
\hline Children under 18 living at home & & $\begin{array}{l}-0.012 \\
(0.053)\end{array}$ & $\begin{array}{l}-0.049 \\
(0.057)\end{array}$ \\
\hline Married & & $\begin{array}{l}-0.041 \\
(0.051)\end{array}$ & $\begin{array}{l}-0.074 \\
(0.055)\end{array}$ \\
\hline Suburban & & $\begin{array}{l}-0.033 \\
(0.052)\end{array}$ & $\begin{array}{l}-0.039 \\
(0.055)\end{array}$ \\
\hline Rural & & $\begin{array}{l}0.060 \\
(0.061)\end{array}$ & $\begin{array}{l}0.070 \\
(0.066)\end{array}$ \\
\hline Observations & 4362 & 4292 & 4037 \\
\hline Wald chi-square & 325.5 & 399.0 & 521.5 \\
\hline
\end{tabular}

See notes to Table 1 . 
Table A5. Probit regressions predicting support for redistribution allowing for type-specific preferences assuming a Stone-Geary utility function and the linear redistribution scheme.

\begin{tabular}{ll}
\hline Log income & $0.693^{* * *}$ \\
& $(0.16)$ \\
Belief that income is caused by effort & $-0.289^{*}$ \\
& $(0.15)$ \\
White & -0.037 \\
& $(0.12)$ \\
Belief* white & $-0.408^{* * *}$ \\
& $(0.16)$ \\
Some college or more & -0.003 \\
& $(0.098)$ \\
Belief*some college or more & $-0.419^{* * *}$ \\
& $(0.13)$ \\
\hline Observations & 2203 \\
Wald chi-square & 289.6 \\
\hline
\end{tabular}

See notes to Table 3. 


\section{Diskussionsbeiträge des Fachbereichs Wirtschaftswissenschaft der Freien Universität Berlin}

2007

2007/1 BESTER, Helmut / Daniel KRÄHMER

Delegation and Incentives

Volkswirtschaftliche Reihe

2007/2 CORNEO, Giacomo / Olivier Jeanne

Symbolic Values, Occupational Choice, and Economic Development Volkswirtschaftliche Reihe

2007/3 NITSCH, Volker

State Visits and International Trade

Volkswirtschaftliche Reihe

2007/4 EISEND, Martin

Methodische Grundlagen und Anwendungen der Generalisierbarkeitstheorie

in der betriebswirtschaftlichen Forschung

Betriebswirtschaftliche Reihe

2007/5 HAASE, Michaela (Hrsg.)

Kritische Reflexionen empirischer Forschungsmethodik

Betriebswirtschaftliche Reihe

2007/6 RENDTEL, Ulrich / Edin BASIC

Assessing the bias due to non-coverage of residential movers in the German Microcensus Panel: An evaluation using data from the Socio-economic Panel Volkswirtschaftliche Reihe

GHOSH, Amit / Ulrich RENDTEL

Unterrichten und Prüfen mit dem Statistiklabor: Ein Erfahrungsbericht

Volkswirtschaftliche Reihef 